\title{
The Effects of Extracellular Magnesium on Gastrointestinal Contractility
}

\section{(1) Ali Özant ${ }^{1}$, (1) Emine Koç²}

1Department of General Surgery, Near East University, Faculty of Medicine, Nicosia, Cyprus

2Department of Physiology, Near East University, Faculty of Medicine, Nicosia, Cyprus

\section{Abstract}

BACKGROUND/AIMS: Magnesium $\left(\mathrm{Mg}^{2+}\right)$ is the second most abundant anion in the human body. It plays important roles including as a cofactor in many critical enzyme systems like energy transfer, storage and utilization. Changes in the concentration of extracellular $\mathrm{Mg}^{2+} \mathrm{may}_{\mathrm{Cause}} \mathrm{many}$ pathological conditions such as neuromuscular hyperactivity, psychiatric disturbances, calcium/potassium abnormalities, and overactivity of cardiac muscle. Many investigations have been conducted on the effects of $\mathrm{Mg}^{2+}$ on cardiac, skeletal and vascular muscle contraction; however, much less is known about the effect of extracellular $\mathrm{Mg}^{2+}$ on gastrointestinal smooth muscle systems and gastrointestinal contractility. In the current study, we aimed to study the effects of extracellular $\mathrm{Mg}^{2+}$ on the isolated ileal responses induced by angiotensin II(ANG) contraction and in response to calcium and sodium channel blockers.

MATERIALS and METHODS: Healthy adult Wistar rats were used in this work. The ileal segments were isolated and suspended in isolated organ tissue-bath. The contractile responses induced with ANG were recorded. To study the effects of extracellular magnesium, the perfusion medium was changed to without magnesium, $2 \mathrm{xMg}$ and $4 \mathrm{xMg}$. In these standard and modified perfusion mediums, the ileal segments were incubated with the calcium channel blocker diltiazem (Benz(othi)azepines) and sodium channel blocker prilocaine (2-(Propylamino)-o-propionotoluidide) and then ANG-induced contraction was recorded.

RESULTS: The results showed that in the Mg-free perfusion medium the ANG-induced contractions were increased and when extracellular magnesium was increased $2 \mathrm{x}$-fold and $4 \mathrm{x}$-fold in the perfusion medium, the ANG-induced responses were significantly decreased. Also, in the standard and modified Mg perfusion medium, the calcium and sodium channel blockers significantly decreased the ANG-induced contractions in isolated ileal segments.

CONCLUSION: Changes in the extracellular magnesium concentration in the perfusion medium significantly affect the gastrointestinal contractility. Without Mg, the contractility was increased, but with $2 x$-fold and $4 x$-fold increases in Mg, the contractility was significantly decreased. Mg had a dose-dependent inhibitory effect on ANG-induced contractions in the isolated ileal segments.

Keywords: Extracellular magnesium concentration, calcium and sodium channel blocker, isolated ileal contractility

To cite this article: Özant A, KoçE. The Effects of Extracellular Magnesium on Gastrointestinal Contractility. Cyprus J Med Sci 2021;6(Suppl 1):58-62

ORCID iDs of the authors: A.Ö. 0000-0002-7746-2719; E.K. 0000-0001-8804-4937. 


\section{INTRODUCTION}

Magnesium $\left(\mathrm{Mg}^{2+}\right)$ is one of the most important and prominent ions in the human organism, such as calcium $\left(\mathrm{Ca}^{2+}\right)$, sodium $(\mathrm{Na})$, and potassium, and is the major cation that is necessary for the function of hundreds of enzyme systems. $\mathrm{Mg}^{2+}$ plays a role in the pathogenesis of hypertension, and a correlation is determined between serum $\mathrm{Mg}^{2+}$ and the incidence of cardiovascular diseases. ${ }^{1}$ Oral $\mathrm{Mg}^{2+}$ intake was shown to act as a natural $\mathrm{Ca}^{2+}$ channel blocker. ${ }^{2}$ Additionally, many drugs, such as diuretics and proton-pomp inhibitors, can cause $\mathrm{Mg}^{2+}$ deficiency ${ }^{3}$ since both $\mathrm{Mg}^{2+}$ and these drugs use the same transport mechanisms in the organism, such as absorption, metabolism, and excretion. Therefore, when a person is taking these drugs, there is a risk of interaction with $\mathrm{Mg}^{2+}$ status. ${ }^{4}$ Additionally, $\mathrm{Mg}^{2+}$ depletion is frequently observed in patients who are hospitalized. Generally, it is secondary to renal or intestinal $\mathrm{Mg}^{2+}$ loss and is particularly seen in patients with diabetes mellitus who have neuromuscular symptoms, hypokalemia, and cardiovascular complications. ${ }^{5}$ $\mathrm{Mg}^{2+}$ treatment is becoming an important adjunct in some conditions, such as eclampsia, cardiovascular diseases, diabetes mellitus, asthma, and others. ${ }^{6}$ The rapid onset of $\mathrm{Mg}^{2+}$ 's effects suggests an extracellular action on $\mathrm{Ca}^{2+}$ entry. ${ }^{7}$

L-type $\mathrm{Ca}^{2+}$ channel blockers are usually used to treat several clinical situations, mainly cardiovascular disease, and specifically, hypertension. L-type $\mathrm{Ca}^{2+}$ channel blockers have been used for many years for cardiovascular disease, thus their side effect profile has been well studied. However, their effects on the contractility of the gastrointestinal tract are less known.

Voltage-gated Na channels are dynamic membrane proteins and are responsible for starting the action potential in all excitable membranes..$^{8}$ Tappenbeck et al. ${ }^{9}$ observed that the contractilityenhancing effects of local anesthetic are based on interaction with smooth muscle membranes, modulated by its molecular structure and lipophilicity. ${ }^{10}$ The ion channels and ion transport systems are located in the cell membranes of the smooth muscle ${ }^{11}$ as in all other excitable membranes. Na fluxes play a small role in smooth muscle contraction of the feline colon; ${ }^{12}$ however, they contribute to the production of slow waves in human interstitial cells of Cajal (ICC)..$^{13}$ The ICC cells present in the human intestine have a mechanosensitive Na channel current and play a role in the control of intestinal motor function. ${ }^{13}$

This study investigated the effects of extracellular $\mathrm{Mg}^{2+}$ concentration on the angiotensin II (ANG)-induced contraction on isolated ileal segments. Additionally, in different extracellular $\mathrm{Mg}^{2+}$ perfusion mediums, the effects of the $\mathrm{Ca}^{2+}$ channel blocker, diltiazem, and $\mathrm{Na}$ channel blocker, prilocaine, were investigated on the amplitude of angiotensin-induced contractions on the isolated rat ileum. As the $\mathrm{Na}$ and $\mathrm{Ca}^{2+}$ channel blockers are widely used, this study aimed to determine their possible effects in different extracellular $\mathrm{Mg}^{2+}$ concentrations on gastrointestinal system motility.

\section{MATERIALS AND METHODS}

In these experiments, Healthy adult Wistar rats $(n=20)$ weighing 150-250 g were used. This study received the approval of the Local Ethics Committee of Near East University (date: 02/20/2020, reference number: 2020/105). The animals were lightly anesthetized with pentobarbital $(35 \mathrm{mg} / \mathrm{kg}$ i.p) and were killed by decapitation and exsanguination. The ileum strips were mounted in an isolated organ bath containing standard Tyrode solution (mM: $\mathrm{NaCl}$ of $137, \mathrm{KCl}$ of $2.68, \mathrm{MgCl}_{2}$ of $1.05, \mathrm{CaCl}_{2}$ of 1.8, $\mathrm{NaH}_{2} \mathrm{PO}_{4}$ of $0.42, \mathrm{NaHCO}_{3}$ of 11.9 , and glucose of 5.5) and were bubbled with $95 \% \mathrm{O}_{2}$ and $5 \% \mathrm{CO}_{2}$ mixture at $370 \mathrm{C}$ at $\mathrm{pH} 7.4$. Four types of Tyrode solutions were used in these experiments: (i) standard, (ii) $\mathrm{Mg}$-free, (iii) 2-fold $\mathrm{Mg}^{2+}$, and (iv) 4-fold $\mathrm{Mg}^{2+}$. In separate experiments, the bath medium was changed to either $\mathrm{Mg}^{2+}$-free (omitting $\mathrm{MgCl}_{2}$ and adding equimolar $\mathrm{NaCl}$ ), or 2-fold $\mathrm{Mg}^{2+}$ and 4-fold $\mathrm{Mg}^{2+}$ (Omitting $\mathrm{NaCl}$ adding equimolar 2-fold, 4-fold $\mathrm{MgCl}_{2}$ ) solutions. The control group used standard Tyrode as the perfusion medium. The ileum pieces contracted with ANG in doses of $1.2 \times 10-8 \mathrm{M}$, which was accepted as the maximal ANG-induced contractions in the control group. Local anesthetic prilocaine was used in doses of $2.3 \times 10-5 \mathrm{M}$. After the addition of the prilocaine doses, ANG was added after a few minutes into the medium and the results were recorded. The $\mathrm{Ca}^{2+}$ channel blocker diltiazem was used in doses of $5.5 \times 10-6 \mathrm{M}$. The ileal segments were washed several times and left for $60 \mathrm{~min}$ before each agent was added into the bath solution. The $\mathrm{Ca}^{2+}$ channel blocker was added first then followed by the addition of prilocaine and ANG into the medium and the results were recorded. These processes were performed in standard Tyrode solution as the control group, $\mathrm{Mg}^{2+}$-free, 2-fold $\mathrm{Mg}^{2+}$, and 4-fold $\mathrm{Mg}^{2+}$ groups.

\section{RESULTS}

The effects of extracellular $\mathrm{Mg}^{2+}$ concentrations on the ANGinduced contractions on the isolated ileal strip were examined in these experiments. Additionally, the effects of $\mathrm{Ca}^{2+}$ channel blocker diltiazem and Na channel blocker prilocaine on ANGinduced contractions in percentage were examined. The ANGinduced percentage contractions in standard Tyrode, $\mathrm{Mg}^{2+}$-free, 2-fold $\mathrm{Mg}^{2+}$, and 4-fold $\mathrm{Mg}^{2+}$ are shown in Figure 1.

In the standard Tyrode solution (control group), when the $\mathrm{Ca}^{2+}$ and $\mathrm{Na}$ channel blockers were separately used, the responses to ANG were significantly reduced. Additionally, when the channel blockers were used together, the ANG-induced contraction significantly decreased. As shown in Figure 1, an increased response to ANG in the $\mathrm{Mg}^{2+}$-free medium was not statistically significant compared to the control group. Further, in the $\mathrm{Mg}^{2+}$ free perfusion medium, when $\mathrm{Ca}^{2+}$ and $\mathrm{Na}$ channel blockers were used either separately or together, the ANG-induced contractions 
were higher than the control group although the difference was not statistically significant.

When 2-fold and 4-fold $\mathrm{Mg}^{2+}$ medium were used, the contractile responses to ANG were significantly decreased in all high $\mathrm{Mg}^{2+}$ perfusion mediums compared to the responses obtained in the standard Tyrode and $\mathrm{Mg}^{2+}$-free perfusion mediums. If the 2-fold and 4-fold $\mathrm{Mg}^{2+}$ perfusion mediums are compared with each other, the ANG-induced contraction decreased but without any significance.

As shown in Figure 1, diltiazem significantly decreased the ANG-induced contractions in all perfusion mediums used. Additionally, prilocaine decreased the ANG-induced contractions in all perfusion mediums.

Statistical analyses were performed with unpaired t-test. Significance values different from the control were accepted as ${ }^{*} p<0.05,{ }^{* *} p<0.01 * * * p<0.001$ vs. values were presented as mean \pm SEM (standard error of mean).

\section{DISCUSSION}

The present study showed that when $\mathrm{Mg}^{2+}$ was omitted from the perfusion medium, the ANG-induced ileal contractions increased, but the responses significantly decreased when Mg was added 2-fold and 4-fold into the perfusion medium. Additionally, when $\mathrm{Ca}^{2+}$ and $\mathrm{Na}$ channel blockers were added to the perfusion medium, the responses significantly decreased in all used mediums.

Our results showed that in the $\mathrm{Mg}^{2+}$-free perfusion medium,

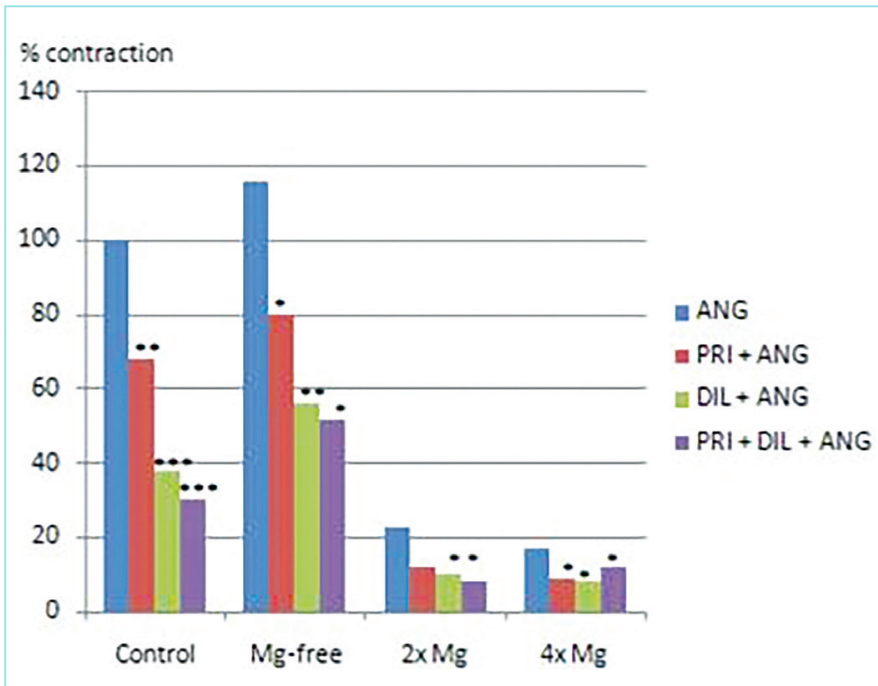

Figure 1. The ANG-induced percentage contraction in standard, $\mathrm{Mg}^{2+}$-free, 2-fold $\mathrm{Mg}^{2+}$, and 4-fold $\mathrm{Mg}^{2+}$ tyrode solutions. The diltiazem and prilocaine effects on ANGinduced percentage contraction.

ANG, Angiotensin; DIL, Diltiazem; PRI, Prilocain; ${ }^{*} p<0.05,{ }^{* *} p$ $<0.01,{ }^{* * *} p<0.001$. the responses to ANG increased. Reducing the concentration of $\mathrm{Mg}^{2+}$ (When $\mathrm{Mg}^{2+}$ is removed) from the normal Tyrode solution enhanced the spontaneous basal activity, whereas the addition of $\mathrm{Mg}^{2+}$ gradually abolished this spontaneous activity. Muscle contraction induced by FS or carbachol was enhanced in $\mathrm{Mg}^{2+}$ free Tyrode solution. The addition of $\mathrm{Mg}^{2+}$ inhibited the response to both forms of stimulation in a dose-dependent manner. ${ }^{14}$

Lin et al. ${ }^{15}$ showed that $\mathrm{Mg}^{2+}$ isoglycyrrhizinate inhibits L-type $\mathrm{Ca}^{2+}$ channels and $\mathrm{Ca}^{2+}$ transient. The effect of $\mathrm{Mg}^{2+}$ is in a dose-dependent manner in myocyte. Also, it was shown that increased internal free $\mathrm{Mg}^{2+}$ concentration partly inhibits the activity of $\mathrm{Na} / \mathrm{Ca}$ exchange, or might limit its ability to trigger Ca release..$^{16}$ Our results showed that as the concentration of $\mathrm{Mg}^{2+}$ in the extracellular fluid increased, the ANG-induced contraction percentage decreased. Additionally, the presence of $\mathrm{Ca}^{2+}$ and $\mathrm{Na}$ channel blockers in the perfusion medium further reduced the responses. Our results showed that the contractile responses significantly decreased with the $\mathrm{Ca}^{2+}$ channel blocker. The inhibitory effects of $\mathrm{Mg}^{2+}$ were potentiated when the $\mathrm{Ca}^{2+}$ concentration in the Tyrode solution was reduced to $0.6 \mathrm{mM}$, whereas increasing the extracellular concentration of $\mathrm{Ca}^{2+}(5.4 \mathrm{mM})$ reduced the inhibitory effects of $\mathrm{Mg}^{2+}$. Yu et al. ${ }^{14}$ demonstrated that the contractile alterations at different concentrations of extracellular $\mathrm{Mg}^{2+}$ correlated with similar changes in intracellular free $\mathrm{Ca}^{2+} .{ }^{14} \mathrm{Heron}^{17}$ postulated that $\mathrm{Mg}^{2+}$ and $\mathrm{Ca}^{2+}$ are dependent on each other as the disrupted balance of one has an impact on the other.

$\mathrm{Ca}^{2+}$ is the most important signaling molecule in all cells and is involved in numerous essential functions including cell life and death. Intracellular $\mathrm{Ca}^{2+}$ should be increased for the contraction of smooth muscle cells like all other muscle cells. Cytosolic $\mathrm{Ca}^{2+}$ increases by opening the $\mathrm{Ca}^{2+}$ channels either in the surface cell membrane or organelles membrane. The smooth muscle cell needs much more $\mathrm{Ca}^{2+}$ from the extracellular medium.

Smooth muscle cells have many $\mathrm{Ca}^{2+}$ channels, such as voltagegated $\mathrm{Ca}^{2+}$ channels and RyRs for increased intracellular $\mathrm{Ca}^{2+}$ concentration. Depolarization causes L-type $\mathrm{Ca}^{2+}$ channels to open enabling $\mathrm{Ca}^{2+}$ to enter down its concentration gradient into cells. The stimulatory signal results in increased cytosolic $\mathrm{Ca}^{2+}$ levels, which activates muscle contraction..$^{18}$ In smooth muscle, $\mathrm{Ca}^{2+}$ enters the cell through many ways, particularly two different types of $\mathrm{Ca}^{2+}$ channels, then activates contractile filaments and induces contraction. These $\mathrm{Ca}^{2+}$ channels are inhibited by $\mathrm{Ca}^{2+}$ channel blockers and/or nitro compounds. $\mathrm{Ca}^{2+}$ inhibits both of these $\mathrm{Ca}^{2+}$ channels and relaxes the muscle. A portion of the smooth muscle contraction is due to the release of $\mathrm{Ca}^{2+}$ from the cellular storage site. Caffeine and norepinephrine release $\mathrm{Ca}^{2+}$ from this store to induce a transient contraction. The contraction induced by caffeine is greatly augmented in the absence of $\mathrm{Mg}^{2+}$. The other effect of $\mathrm{Mg}^{2+}$ deficiency is to 
inhibit the effects of various vasodilators. Vascular endothelium releases a substance that relaxes vascular smooth muscle and this relaxation is also inhibited by $\mathrm{Mg}^{2+}$ deficiency. Thus, $\mathrm{Mg}^{2+}$ has multiple sites, and the mechanisms of action in smooth muscle are still controversial. ${ }^{19}$

In gastrointestinal smooth muscle, like all in smooth muscles, the upstroke action potential is principally mediated by $\mathrm{Ca}^{2+}$ influx through voltage-dependent L-type $\mathrm{Ca}^{2+}$ channels and is responsible for the initiation of contraction. $\mathrm{Ca}^{2+}$ channel blockers or $\mathrm{Ca}^{2+}$ antagonists reduce smooth muscle contraction by inhibiting $\mathrm{Ca}^{2+}$ ions fluxes. ${ }^{20}$ In this study, diltiazem was used as a $\mathrm{Ca}^{2+}$ channel blocker and results indicated that the ANG-induced contraction was reduced in all the used perfusion mediums. Diltiazem blocked the L-type $\mathrm{Ca}^{2+}$ channels. ${ }^{20}$

Our study results showed that when $\mathrm{Na}$ ions were blocked by prilocaine Na channel blocker, the ANG-induced contractions significantly reduced. Several investigations have reported the effects of local anesthetic on Na channels in particular. ${ }^{21-23}$ The role of $\mathrm{Na}$ fluxes in smooth muscle contraction is controversial; however, it has been shown to play a role in the generation of slow-wave in human ICC cells. ${ }^{13}$

\section{CONCLUSION}

Changing the extracellular $\mathrm{Mg}^{2+}$ concentration affects the ANGinduced contraction in isolated ileal segments. In the $\mathrm{Mg}^{2+}$-free perfusion medium, the ANG-induced contraction increased. The addition of 2-fold $\mathrm{Mg}^{2+}$ and 4-fold $\mathrm{Mg}^{2+}$ into the perfusion medium significantly decreased the responses. The $\mathrm{Ca}^{2+}$ channel blocker diltiazem and $\mathrm{Na}$ channel blocker prilocaine decreased the isolated rat ileal contractility. Diltiazem decreased $\mathrm{Ca}^{2+}$ entry into the gastrointestinal smooth muscle as with any other smooth muscle. Prilocaine decreased $\mathrm{Na}$ and probably $\mathrm{Ca}^{2+}$ entry into the cells. This study showed that changing the concentration of extracellular $\mathrm{Mg}^{2+}$ ions affects gastrointestinal contractility. However, further studies are needed to better clarify the role of extracellular $\mathrm{Mg}^{2+}$ and it should be further confirmed by human investigations.

\section{Main Points}

- $\mathrm{Mg}^{2+}$ ions play an important role in many enzyme systems in the organism.

- The angiotensin-induced contractions in the $\mathrm{Mg}^{2+}$-free perfusion medium increased in the isolated gastrointestinal segments.

- When $\mathrm{Mg}^{2+}$ ions increased in the perfusion medium either 2-fold or 4-fold, the responses to ANG significantly decreased
- $\mathrm{Mg}^{2+}$ ions play an important role in gastrointestinal contractility.

\section{ETHICS}

Ethics Committee Approval: This study received the approval of the Local Ethics Committee of Near East University (date: 02/20/2020, reference number: 2020/105).

Informed Consent: Animal experiment.

Peer-review: Externally peer-reviewed.

\section{Authorship Contributions}

Concept: E.K., A.Ö.; Design: E.K.; Supervision: E.K., A.Ö.; Resource: E.K., A.Ö.; Materials: E.K., A.Ö.; Data Collection: E.K.; Analysis: E.K.; Literature Search: E.K., A.Ö.; Writing: E.K., A.Ö; Critical Reviews: E.K.

\section{DISCLOSURES}

Financial Disclosure: The author declared that this study had received no financial support.

Conflict of Interest: The authors declare no conflict of interest.

\section{REFERENCES}

1. Cunha AR, Umbelino B, Correia ML, Neves MF. Magnesium and vascular changes in hypertension. Int J Hypertens. 2012;2012:754250.

2. Houston M. The role of magnesium in hypertension on cardiovascular disease. J Clin Hypertens. 2011;13:843-847.

3. Bai JP, Hausman E, Lionberger R, Zhang X. Modeling and stimulation of the effect of proton pump inhibitors on magnesium homeostasis. 1.oral absorption of magnesium. Mol Pharmacol. 2012;3:3495-3505.

4. Grober U. Magnesium and drugs. Int J Mol Sci. 2019;28/20:9. pii: E2094.

5. Nadler JL, Rude RK. Disorders of magnesium metabolism. Endocrinol Metab Clin North Am. 1995;24:623-641.

6. Lourenco R, Camilo ME. Magnesium:physiological and clinical relevance. 1: homeostasis and alterations in the metabolism of magnesium. Houston M. The role of magnesium in hypertension and cardiovascular disease. J Clin Hypertens. 2011;13:843-847.

7. Osaghae BE, Arrowsmith S, Wray S. Gestational and hormonal effects on magnesium sulfate's ability to inhibit mouse uterine contractility. Reprod Sci. 2019 Feb 17;1933719119828089. doi: 10.1177/1933719119828089

8. Nau C, Wang GK. Interaction of local anesthetics with voltage-gated Na channels. J Membr Biol. 2004;201:1-8.

9. Tappenbeck K, Hoppe S, Reichert C, Feige K, Huber K. In vitro effects of lidocaine on contractility of circular and longitudinal equine intestinal smooth muscle. Vet. 2013;198:170-175.

10. Guschlbauer M, Hoppe S, Geburek F, Feige K, Huber K. In vitro effects of lidocaine on the contractility of equine jejuna smooth muscle challenged by ischemia-reperfusion injury. Equine Vet J. 2010;42:53-58.

11. Beyder A, Farrugia G. Targeting ion channels for the treatment of gastrointestinal motility disorders. Therap Adv Gastroenterol. 2012;5:5-21. 
12. Snape WJ, Tan St. Role of sodium or calcium in electrical depolarization of feline colonic smooth muscle. American Journal of Physiology. Am J Physiol Gastrointest Liver Physiol. 1886;249:C66-C72.

13. Strege PR, Ou YJ, Sha L, et al. Sodium current in human intestinal interstitial cells of cajal. American Journal of Physiology. Am J Physiol Gastrointest Liver Physiol. 2003;285:G1111-G1121.

14. Yu HJ, Hypolite JA, Wein AJ, Levin RM. Effect of magnesium ions on rabbit detrusor contractility and intracellular free calcium. Pharmacology. 1995;51:186-194.

15. Lin Y, Zhang Y, Song Q, et al. Magnesium isoglycyrrhizinate inhibits L-type Ca channels, ca transients, and contractility but not hERG K channels. Arch Pharm Res. 2017;40:1135-1145.

16. Howarth FC, Levi AJ. Internal free magnesium modulates the voltage dependence of contraction and Ca transient in rabbit ventricular myocytes. Pflügers Archiv. 1998;435:687-698.

17. Heron V. Fluid and electrolyte disorders. Calcium, Phosphate and Magnesium Disorders. 2018. Doi: 10.5772/intechopen.81173. Available at: https://www. intechopen.com/chapters/63945
18. Kuo IY, Ehrlich BE. Signaling in muscle contraction. Cold Spring Harb Perspect Biol. 2015;7:a006023.

19. Karaki H. Magnesium as a modifier of smooth muscle contractility. Microcirc Endothelium Lymphatics. 1989;5:77-97.

20. Godfraind T. Calcium Channel Blockers in cardiovascular Pharmacotherapy. J Cardiovasc Pharmacol Therap. 2014;19:501-515.

21. Muroi Y, Chanda B. Local anesthetic disrupt energetic coupling between the voltage-sensing segments of a sodium channel. J Gen Physiol. 2009;133:1-15.

22. Lee S, Goodchild SJ, Samuel CA, Ahern CA. Local anesthetic inhibition of a bacterial sodium channel. J Gen Physiol. 2012;139/6:507-516.

23. Zamponi GW, Striessnig J, Koschak A, Dolphin AC. The physiology, pathology and pharmacology of voltage-gated calcium channels and their future therapeutic potential. Pharmacol Rev. 2015;67:821-870. 